\title{
African evolutionary history inferred from whole genome sequence data of 44 indigenous African populations
}

Shaohua Fan ${ }^{1,2}$, Derek E. Kelly ${ }^{1}$, Marcia H. Beltrame', Matthew E. B. Hansen ${ }^{1}$, Swapan Mallick ${ }^{3,4,5}$, Alessia Ranciaro ${ }^{1}$, Jibril Hirbo ${ }^{1,6}$, Simon Thompson?', William Beggs ${ }^{1}$, Thomas Nyambo ${ }^{7}$, Sabah A. Omar $^{8}$, Dawit Wolde Meskel ${ }^{9}$, Gurja Belay ${ }^{9}$, Alain Froment ${ }^{10}$, Nick Patterson ${ }^{4}$, David Reich ${ }^{3,4,5}$ and Sarah A. Tishkoff ${ }^{1,11^{*}}$ (D)

\begin{abstract}
Background: Africa is the origin of modern humans within the past 300 thousand years. To infer the complex demographic history of African populations and adaptation to diverse environments, we sequenced the genomes of 92 individuals from 44 indigenous African populations.

Results: Genetic structure analyses indicate that among Africans, genetic ancestry is largely partitioned by geography and language, though we observe mixed ancestry in many individuals, consistent with both short- and long-range migration events followed by admixture. Phylogenetic analysis indicates that the San genetic lineage is basal to all modern human lineages. The San and Niger-Congo, Afroasiatic, and Nilo-Saharan lineages were substantially diverged by 160 kya (thousand years ago). In contrast, the San and Central African rainforest hunter-gatherer (CRHG), Hadza hunter-gatherer, and Sandawe hunter-gatherer lineages were diverged by 120-100 kya. Niger-Congo, Nilo-Saharan, and Afroasiatic lineages diverged more recently by 54-16 kya. Eastern and western CRHG lineages diverged by $\sim 50-$ $31 \mathrm{kya}$, and the western CRHG lineages diverged by 18-12 kya. The San and CRHG populations maintained the largest effective population size compared to other populations prior to 60 kya. Further, we observed signatures of positive selection at genes involved in muscle development, bone synthesis, reproduction, immune function, energy metabolism, and cell signaling, which may contribute to local adaptation of African populations.
\end{abstract}

Conclusions: We observe high levels of genomic variation between ethnically diverse Africans which is largely correlated with geography and language. Our study indicates ancient population substructure and local adaptation of Africans.

Keywords: African populations, Genomic variation, Human evolution, Local adaptation, Demographic history, Effective population size, Whole genome sequencing

\section{Introduction}

Paleontological and genetic evidence indicates that modern humans originated in Africa within the past 300 thousand years (ky) [1] and spread across the globe within the last $100 \mathrm{ky}$ [2]. Therefore, modern humans have continuously inhabited the African continent longer than any other region [2]. Africans have high levels of genetic, cultural, and linguistic diversity [3] as well as extensive population

\footnotetext{
* Correspondence: tishkoff@pennmedicine.upenn.edu

'Department of Genetics, University of Pennsylvania, Philadelphia, PA 19104, USA

${ }^{11}$ Department of Biology, University of Pennsylvania, Philadelphia, PA 19104 USA

Full list of author information is available at the end of the article
}

structure [4]. More than 2000 ethnolinguistic groups have been identified in Africa, consisting of around one third of the world's languages [4]. Almost all African languages are classified into four major phyla: Afroasiatic, Nilo-Saharan, Niger-Congo, and Khoesan [5]. Afroasiatic languages are mainly spoken by agro-pastoralist and agriculturalist populations in northern and eastern Africa. Nilo-Saharan languages are spoken mainly by pastoralists in central and eastern Africa. The Niger-Congo phylum, with 1436 languages, is the largest language phylum in the world. The Bantu languages, which are a subfamily of the Niger-Congo phylum, are a collection of around 500 closely related languages and are spoken by at least 200

(C) The Author(s). 2019 Open Access This article is distributed under the terms of the Creative Commons Attribution 4.0 International License (http://creativecommons.org/licenses/by/4.0/), which permits unrestricted use, distribution, and 
million people due to the migration within the last four thousand years of Bantu-speaking people across eastern and southern sub-Saharan Africa (a.k.a. the Bantu expansion) $[4,6]$. The Khoesan language phylum, characterized by click consonants, is the smallest of the four language phyla in Africa. Populations classified as speaking Khoesan languages include hunter-gatherer populations in southern Africa, referred to as "San," as well as the Hadza and Sandawe who are current and former hunter-gatherer populations, respectively, though their languages are highly divergent and their classification as one language family is contentious $[5,7,8]$.

African populations practice a wide variety of subsistence patterns including hunting-gathering, pastoralism, fishing, agriculture, and agro-pastoralism $[4,9,10]$. Due to their large long-term population sizes and deep population divergence times compared to non-Africans, Africans have the highest level of genetic diversity in comparison to any other populations in the world [11]. At least 14 genetically defined ancestral clusters were identified in African populations [4]. Due to extensive migration and admixture events, most Africans are genetically heterogeneous with diverse ancestries [4]. Multiple studies have shown that the population substructure evident in African populations today had already begun to develop before anatomically modern humans migrated out of Africa 50-100 kya (thousand years ago) [12-14]. Studying human evolution in Africa also provides numerous textbook examples of local adaptation [15-18]. For example, lactase persistence (LP), the ability to digest lactose in adulthood, is common in populations practicing a pastoralist subsistence but is rare in hunter-gatherer populations $[15,16]$.

Because all modern humans originated in Africa, a better understanding of the pattern of genetic variation in African genomes is important not just for understanding African demographic history but also, more generally, for deepening our understanding of the origin of modern humans, the genetic basis of adaptation to different environments, and genetic factors influencing disease susceptibility $[2,10,19]$. High-throughput sequencing technologies have provided valuable resources for studying genetic variation in Africans. For example, the 1000 Genome project has sequenced five indigenous African populations, including Esan, Gambian, Luhya, Mende, and Yoruba (all of which speak Niger-Congo languages and originated from West and Central Africa within the past $4 \mathrm{ky}$ ), and confirmed that Africans harbor a greater number of genetic variants, both single nucleotide polymorphisms (SNPs) and structural variants (SVs), compared to populations from other continents [20]. A high coverage sequencing study of the genomes of 15 individuals from three African hunter-gatherer populations, central African rainforest hunter-gatherer
(CRHG), and Khoesan-speaking Hadza and Sandawe in east Africa, identified novel genetic diversity and signatures of local adaptation in these populations [21]. The African Genome Variation Project conducted whole genome sequencing at low coverage in seven populations [22]. Nonetheless, these studies only cover a small proportion of the genetic diversity in Africa.

To extend our knowledge of patterns of genomic diversity in Africa, we generated high coverage $(>30 \times)$ genome sequencing data from 43 geographically diverse Africans originating from 22 ethnic groups, representing a broad array of ethnic, linguistic, cultural, and geographic diversity (Additional file 1: Table S1). These include a number of populations of anthropological interest that have never previously been characterized for high-coverage genome sequence diversity such as Afroasiatic-speaking El Molo fishermen and Nilo-Saharan-speaking Ogiek hunter-gatherers (Kenya); Afroasiatic-speaking Aari, Agaw, and Amhara agropastoralists (Ethiopia); Niger-Congo-speaking Fulani pastoralists (Cameroon); Nilo-Saharan-speaking Kaba (Central African Republic, CAR); and Laka and Bulala (Chad) among others (Additional file 1: Table S1). We integrated this data with 49 whole genome sequences generated as part of the Simons Genome Diversity Project (SGDP) [14] (Fig. 1). Our new dataset, consisting of 92 individuals from 44 indigenous African populations speaking languages belonging to the four main language phyla and practicing diverse subsistence patterns, greatly expands representation of whole genome sequences from geographically, culturally, and linguistically diverse Africans. We constructed phylogenetic relationships and inferred the population structure, effective population size, and divergence time of these populations. In addition, we identified signatures of positive selection in populations that have adapted to diversified environments and diets.

\section{Results and discussion}

We analyzed high-coverage whole genome sequencing data from 92 individuals from 44 indigenous African populations and a comparative dataset consisting of 62 west Eurasian individuals from 32 populations represented in the SGDP [14]. We identified 26,230,650 SNPs and selected a set of 7,497,970 SNPs, after pruning based on linkage disequilibrium (LD), for use in further analyses.

\section{Phylogenetic relationship of African populations}

A set of 4,587,274 SNPs for which we could make a high confidence determination of an ancestral allele were used to construct the phylogenetic relationship of Africans and Eurasians using a neighbor-joining (NJ) method, which assumes no admixture events. Thus, individuals who cluster near each other in the tree could either share a recent 


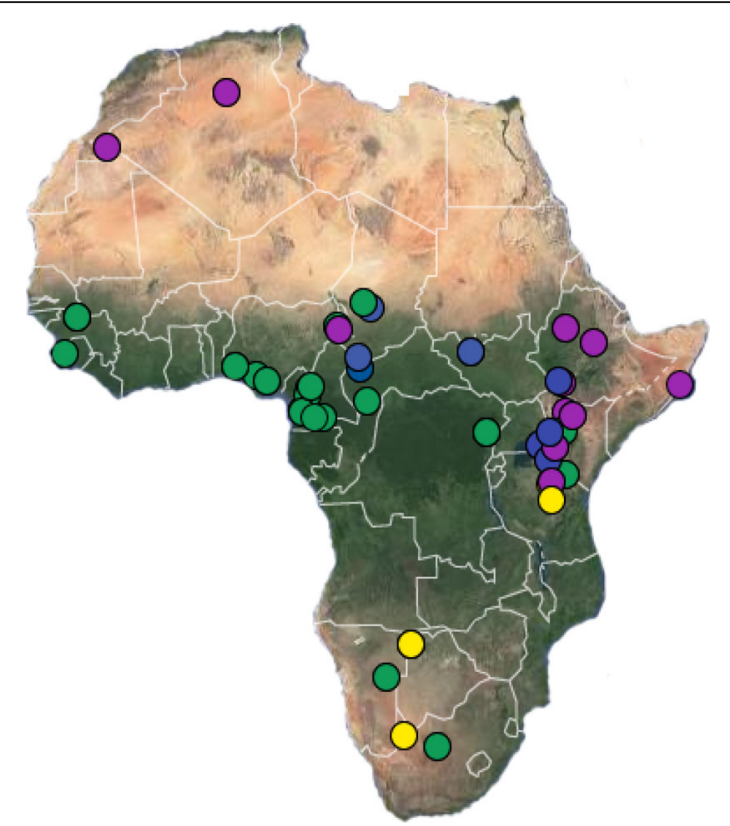

Afroasiatic

Nilo-Saharan

Niger-Congo

Khoesan

Fig. 1 Locations of samples included in this study. Each dot is an individual and the color indicates the language classification

common ancestry and/or experienced gene flow. The resolution of the reconstruction is excellent; bootstrap values of most nodes are greater than 90 . The San lineage (including Khomani San and Jul'hoan) is the basal lineage of all modern human lineages. The other African populations mainly cluster in the tree based on their current geographic location, with the exception of the CRHG and some pastoralist/agro-pastoralist populations such as the Mada and Luo, the latter of which have migrated over long distances and admixed with neighboring populations. We found that the CRHG populations from central Africa, including the Mbuti from the Demographic Republic of Congo (DRC), Biaka from the CAR, and Baka, Bakola, and Bedzan from Cameroon, also form a basal lineage in the phylogeny. The other two hunter-gatherer populations, Hadza and Sandawe, living in Tanzania, group with populations from eastern Africa (Fig. 2). The two Nilo-Saharan-speaking populations, the Mursi from southern Ethiopia and the Dinka from southern Sudan, group into a single cluster, which is consistent with archeological data indicating that the migration of Nilo-Saharan populations to eastern Africa originated from a source population in southern Sudan in the last 3000 years [4, 23-25]. The Fulani people are traditionally nomadic pastoralists living across a broad geographic range spanning Sudan, the Sahel, Central, and Western Africa. The Fulani in our study, sampled from Cameroon, clustered with the Afroasiatic-speaking populations in East Africa in the phylogenetic analysis, indicating a potential language replacement from Afroasiatic to Niger-Congo in this population (Fig. 2). Prior studies suggest a complex history of the Fulani; analyses of Y chromosome variation suggest a shared ancestry with Nilo-Saharan and Afroasiatic populations [24], whereas mtDNA indicates a West African origin [26]. An analysis based on autosomal markers found traces of West Eurasian-related ancestry in this population [4], which suggests a North African or East African origin (as North and East Africans also have such ancestry likely related to expansions of farmers and herders from the Near East) and is consistent with the presence at moderate frequency of the $-13,910 \mathrm{~T}$ variant associated with lactose tolerance in European populations $[15,16]$. Phylogenetic reconstruction of the relationship of African individuals under a model allowing for migration using TREEMIX [27] largely recapitulates the NJ phylogeny with the exception of the Fulani who cluster near neighboring Niger-Congo-speaking populations with whom they have admixed (Additional file 2: Figure S1). Interestingly, TREEMIX analysis indicates evidence for gene flow between the Hadza and the ancestors of the Ju|'hoan and Khomani San, supporting genetic, linguistic, and archeological evidence that Khoesan-speaking populations may have originated in Eastern Africa [28-30].

\section{Population structure in African populations}

Based on PCA analysis, we found 12 significant principal components ( $P$ value $<0.05$, Tracy-Widom distribution) [31] (Additional file 2: Figure S2). The first PC separates the African and non-African populations, with populations from the Middle East clustering in between. The second 


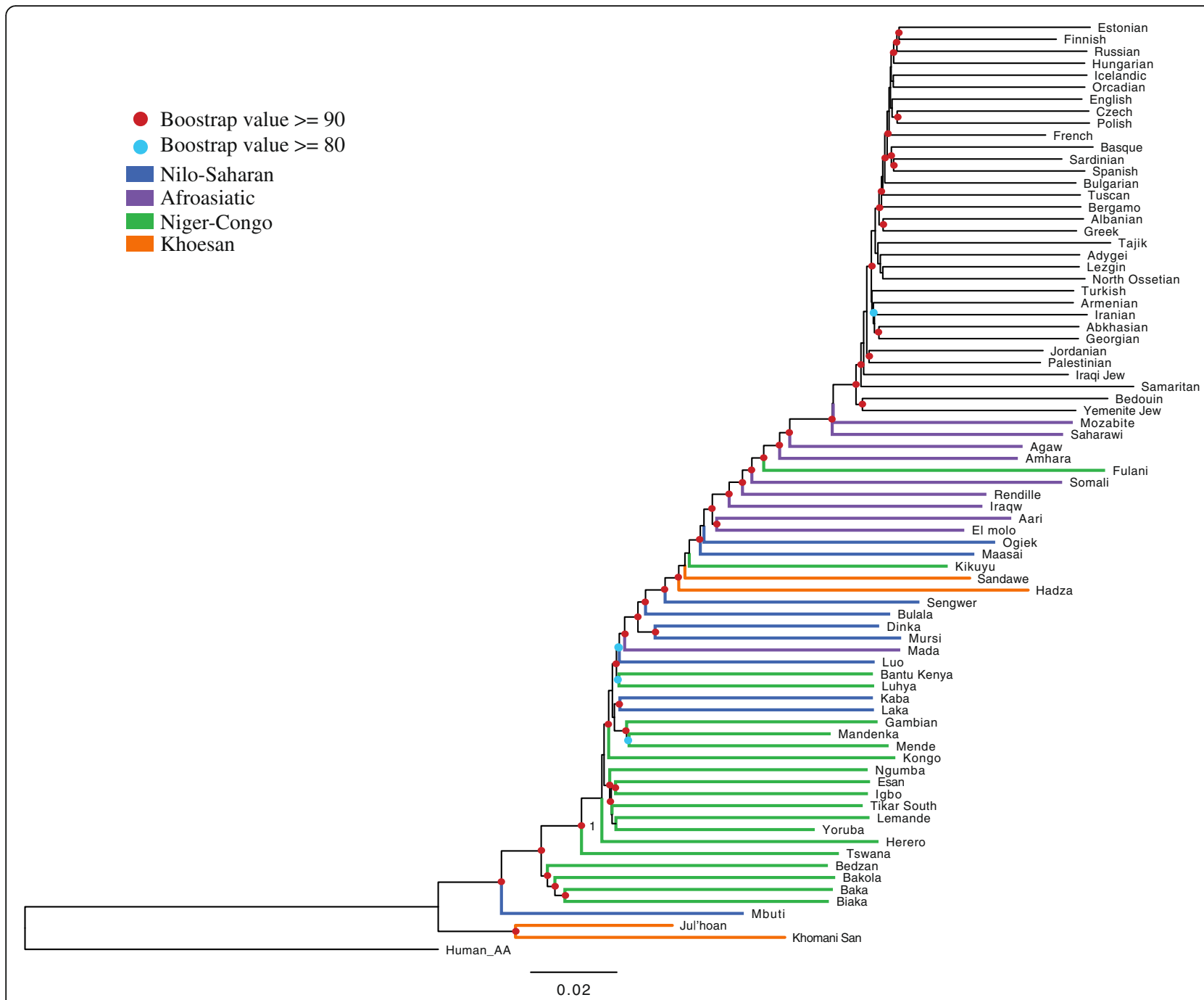

Fig. 2 Phylogenetic relationship of 44 African and 32 west Eurasian populations determined by a neighbor joining analysis assuming no admixture. Here, the dots of each node represent bootstrap values and the color of each branch indicates language usage of each population. Human_AA human ancestral alleles

PC distinguishes the San populations (both Khomani San and Ju|'hoan) from the rest of the populations. PC3 separates CRHG individuals (including both eastern and western CRHG) from other Africans and PC4 distinguishes eastern and western CRHG individuals (Fig. 3).

The ADMIXTURE analysis at $K=2$ separates the African and West Eurasian populations (Fig. 4, Additional file 2: Figure S3). However, a substantial proportion of West Eurasian-related ancestry was observed in populations located in northern Africa, reflecting historical gene flow among populations in these regions [4, 32]. African hunter-gatherer populations (Khomani San, Ju|'hoan, Sandawe, Hadza, and CRHG) are distinguished from the rest of the populations at $K=3$. This observation is consistent with previous studies based on autosomal, mitochondrial, and Y-chromosomal markers indicating evidence of ancient-shared ancestry [4, 12, 13, 33]. From $K=5$, CRHG populations emerge as a single cluster (Fig. 4). With increasing $K$ values, the populations are largely grouped by their current language usage but with the same exceptions as described above for the phylogenetic analysis. We find that Bantu-associated ancestry (green bars) is widely spread across populations in eastern and southern Africa. This observation is consistent with archeological and linguistic evidence indicating an expansion of Niger-Congo Bantu-speaking people, which may have originated in the Cross River Valley, a region between South East Nigeria and Western Cameroon, and then dispersed to equatorial, eastern, and southern Africa within the past 3-5 ky [34-36]. Consistent with a proposed Bantu migration, we observe that NigerCongo ancestry is at the greatest level in western and 

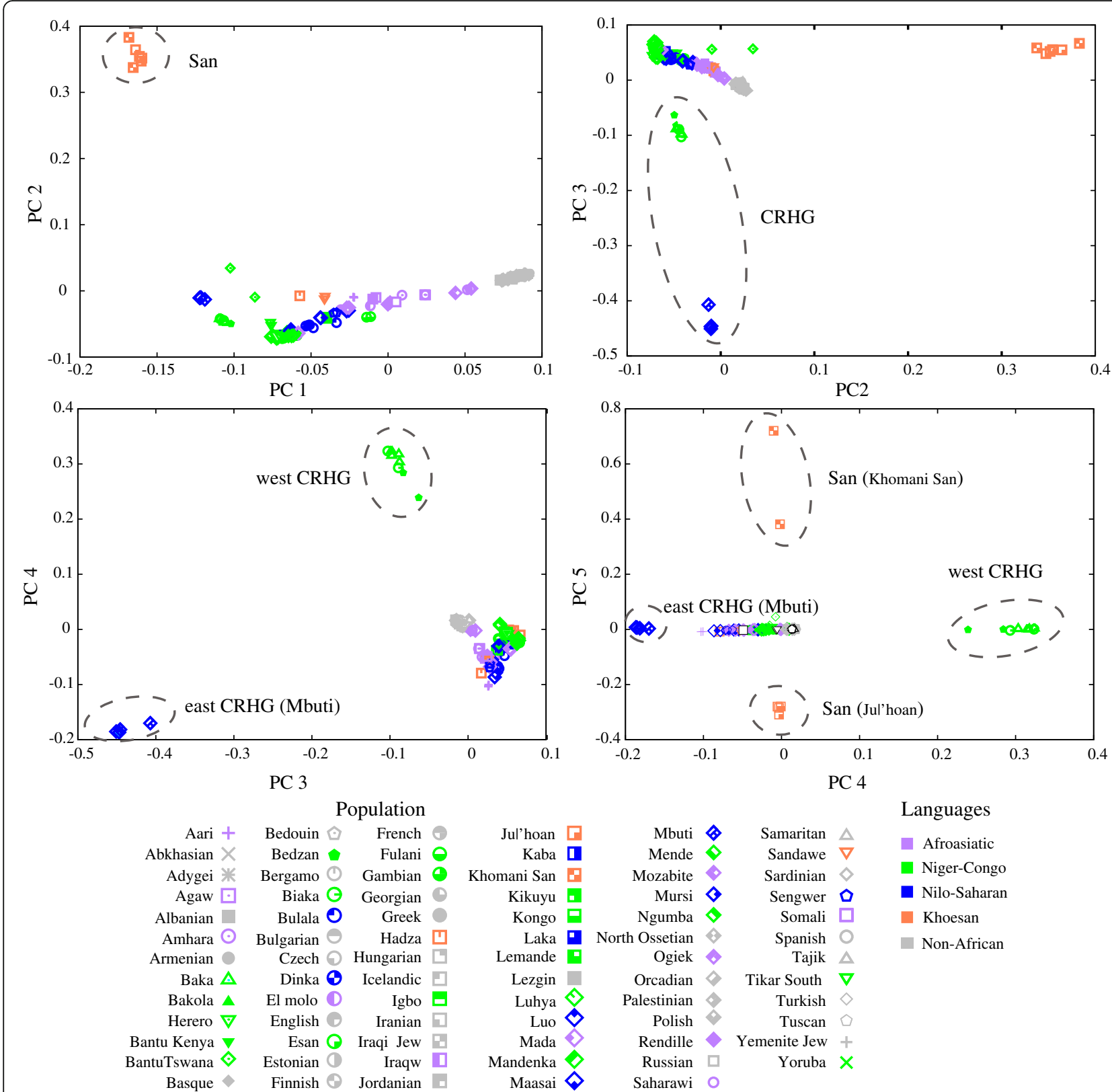

Fig. 3 Principal component analysis of 44 African and 32 west Eurasian populations using principal component analysis. Each dot represents an individual and color of dots represents language usage. PC1 separates the African and western Eurasian populations, with Middle-Eastern populations in between. PC2 distinguishes the San populations (both Khomani San and Jul'hoan) from other Africans. CRHG individuals (including both eastern and western $\mathrm{CRHG}$ ) separate with other Africans at PC3

central African populations (such as Tikar and Lemande) and decreases in eastern (such as Bantu Kenya, Luo, Luhya) and southern (such as Bantu Tswana) African populations. Our ADMIXTURE analyses also suggest that the Sahel-Sudan belt has been a corridor of bidirectional migrations, consistent with [25]. The Sudanese Dinka population has the highest Nilo-Saharan-associated ancestry (blue bars, $K=7$ ), which decreases in the East African populations (such as Massai and Luo) and the Western
African populations (such as Kaba, Luka, and Bulala), consistent with migration from Sudan westward $\sim 7$ kya [37] and eastward into Ethiopia, Kenya, and Tanzania within the past $3 \mathrm{ky}$ [4]. Eastern African populations, such as the Luo, Kikuyu, and Bantu from Kenya, show the highest level of admixture in Africa, which reflects the successive migration and admixture events of Bantu, Nilo-Saharan, and Afroasiatic populations into this region within the past 5 ky $[4,35]$. 


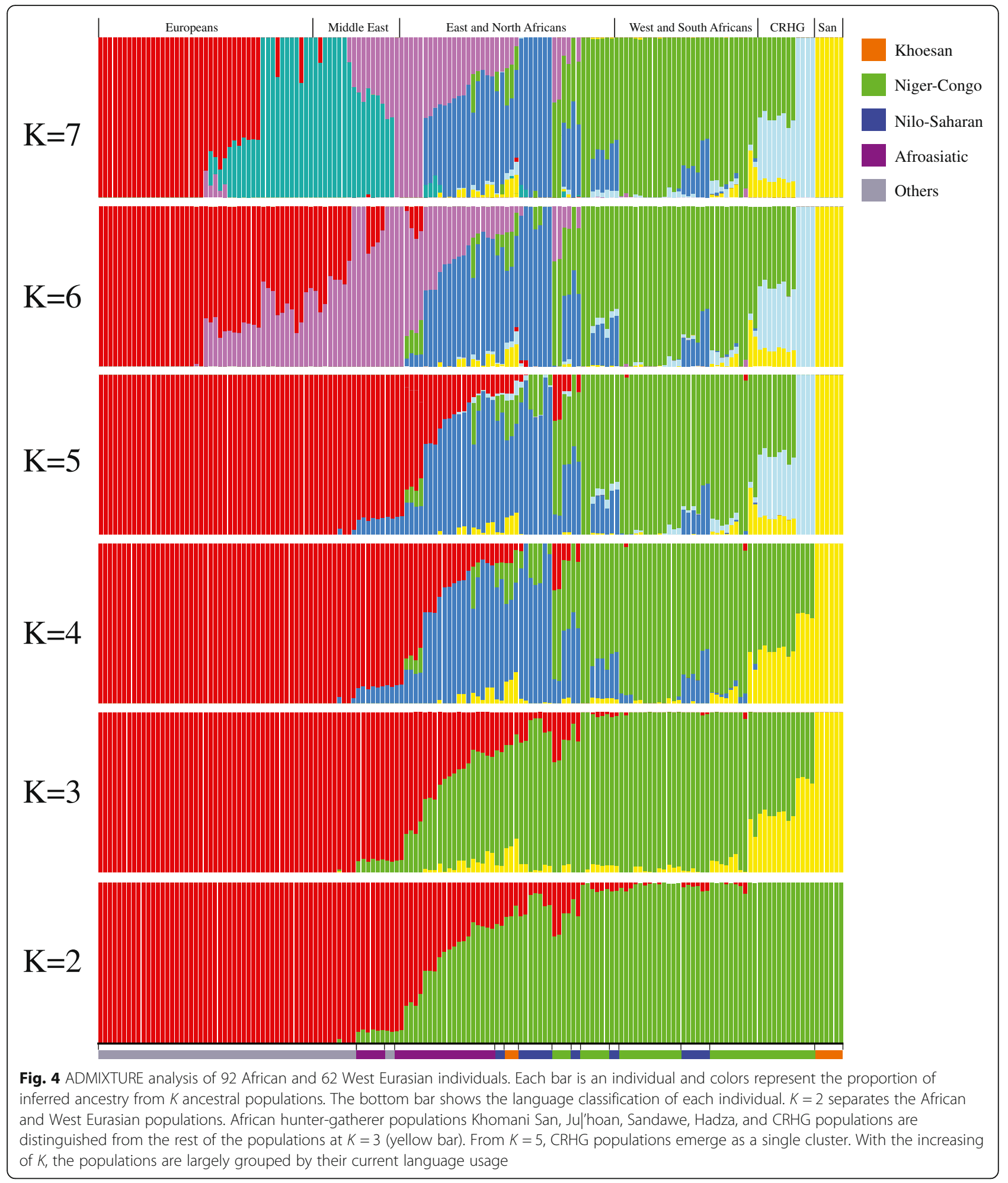

\section{Effective population size ( $\mathrm{Ne}$ ) and divergence times}

Using the multiple sequentially Markovian coalescent (MSMC) method [38], we found that the $\mathrm{Ne}$ of Africans started to diverge around 200 kya (Fig. 5), which is consistent with a model of an early emergence of population structure in Africa after the origin of modern humans $[4,39]$. Between $\sim 200$ and $\sim 60 \mathrm{kya}$, the ancestors of Africans who today speak languages belonging to the four major language phyla experienced a common population bottleneck, but not all the populations were affected 


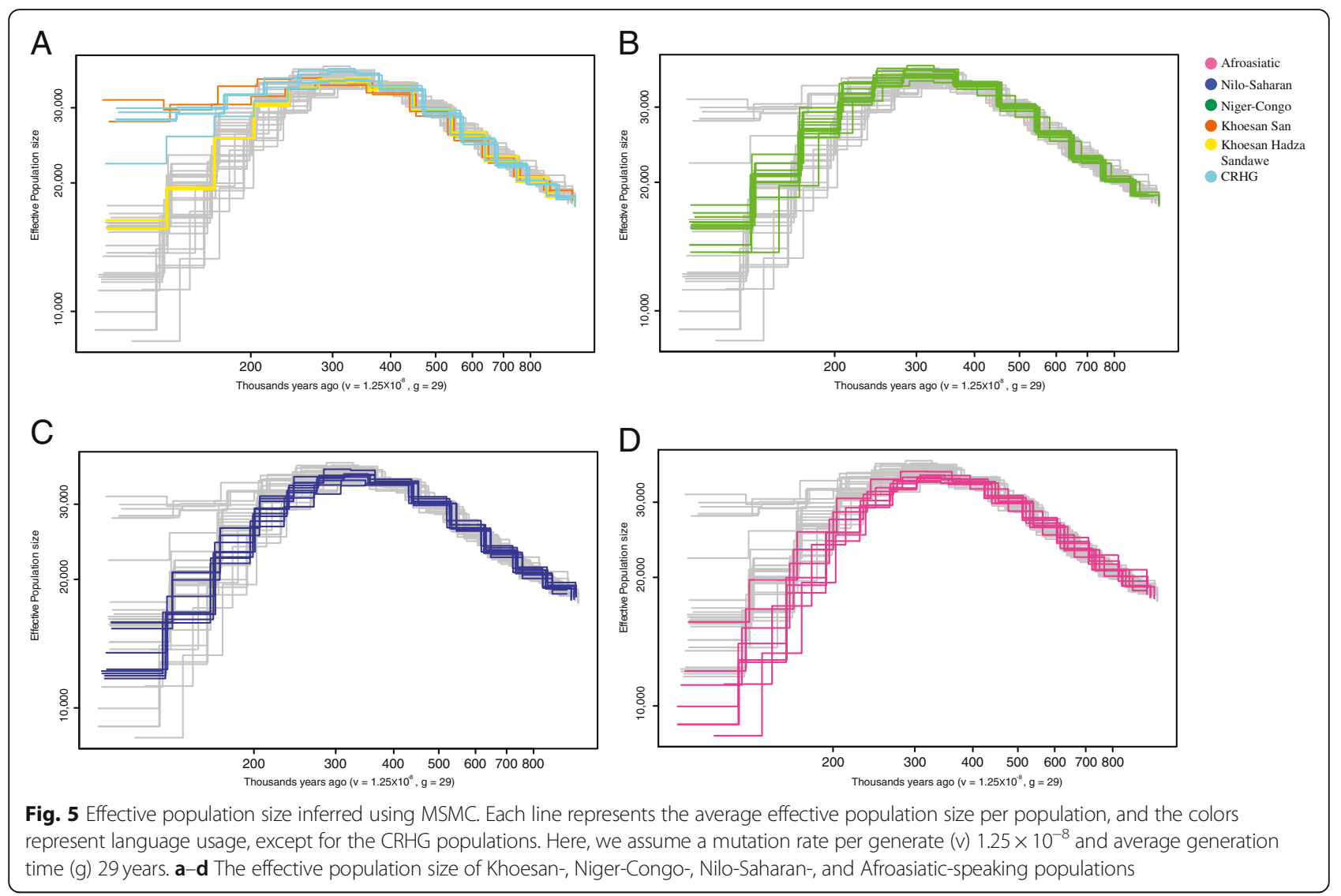

equally (Fig. 5). The San (including both Khomani San and Jul'hoan) maintained the largest $\mathrm{Ne}$ in this period compared to other populations (Fig. 5a), consistent with prior studies $[13,40]$. In addition, we infer that the CRHG populations (including Biaka, Baka, Mbuti, Bedzan, and Bakola, the cyan lines in Fig. 5a), maintained a relatively large $N e$, which is consistent with higher level of genetic diversity in these populations in comparison to other Sub-Saharan populations [13, 21, 41, 42]. Compared to the San and CRHG populations, the inferred ancestral $\mathrm{Ne}$ of the Hadza and Sandawe (Fig. 5a, Additional file 2: Figure S4), Niger-Congo-speaking (Fig. 5b) and Nilo-Saharan-speaking populations were lower in this period (Fig. 5c). Afroasiatic-speaking populations (Fig. 5d) in north Africa have the lowest $\mathrm{Ne}$, which is also reflected in the elevated LD and the reduction of haplotype diversity in these populations compared to other SubSaharan African populations [13, 43, 44]. The low $\mathrm{Ne}$ in Afroasiatic-speaking populations likely reflect the recent migration and admixture with non-African and north African populations (Fig. 4), whose $\mathrm{Ne}$ is much lower than Sub-Saharan Africans [39, 45].

Consistent with the $\mathrm{Ne}$ analysis, an early emergence of population structure in Africa is supported by the relative cross coalescence rate (RCCR) analysis in MSMC. RCCR models the genetic separation between populations by the ratio of within- and cross-population coalescence rates [38]. For example, an RCCR equal to $50 \%$ indicates half of the lineages between a pair of populations descend from a common ancestor. If we consider the time at which $50 \%$ of the lineages coalesce (75-25\% in parentheses) [14], we estimate that the ancestors of the San and the ancestors of the NigerCongo, Nilo-Saharan, and Afroasiatic populations were substantially diverged by $\sim 120-100 \quad(160-44)$ kya (Fig. 6a). This estimation agrees with results of previous TMRCA analyses based on mtDNA [33], Y chromosome [46], autosomal microsatellites [47], large-scale SNP genotype data [42], and whole genome sequences [14, 39]. A recent study based on an ancient unmixed San sample at $\sim 2$ kya suggests more ancient splits between San and other African populations (350 to 260 kya) [48]. If we consider the earliest evidence of population divergence (when RCCR becomes less than one), we observe divergence of the ancestors of current San huntergatherers (including both Khomani San and Ju|'hoan) and the ancestors of Niger-Congo-, Nilo-Saharan-, and Afroasiatic-speaking populations at $\sim 200$ kya (Fig. 6a). In comparison, the inferred divergence time between the San and other African hunter-gatherer populations, such as the CRHG, Hadza, and Sandawe, was inferred to be more recent, though still ancient at 85-68 (120-44) kya 

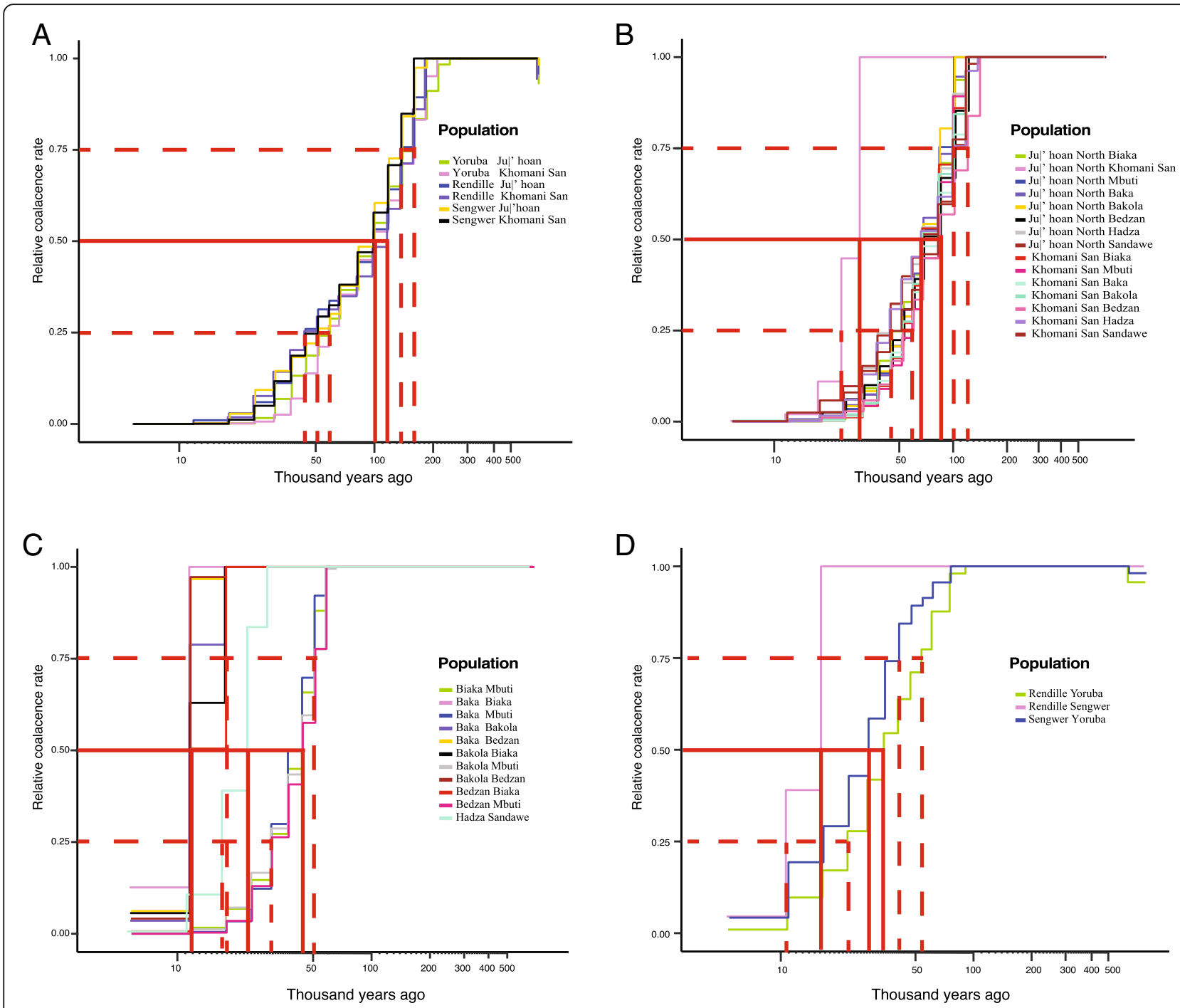

Fig. 6 Relative cross-coalescence rate (RCCR) in African populations. Between the San and non-Khoesan-speaking populations (a); between the San and other African hunter-gatherer populations (b); between the CRHG populations and between the Hadza and Sandawe populations (c); between the Nilo-Saharan-, Niger-Congo-, and Afroasiatic-speaking populations (d)

(Table 1). The divergence between the ancestors of Jul'hoan and Khomani San occurred at 30 (30-24) kya, consistent with prior estimations based on genomic analyses of San populations [49,50]. Our estimation of times of divergence between eastern and western CRHG at $\sim 44(51-31)$ kya and between the western CRHG populations at $\sim 12(18-12)$ kya are comparable to previous estimates $[41,42,51,52]$. In addition, similar to the estimates based on the $\mathrm{Y}$ chromosome and mtDNA variation [12], the two east African Khoesan-speaking populations, the Hadza and Sandawe, diverged $\sim 23$ (23-17) kya (Table 1) [12, 28]. Although currently, these African hunter-gatherer populations are geographically isolated, analyses based on mitochondrial, Y chromosomal, and autosomal marks suggest these populations could be the remnants of a historically widespread population of hunter-gatherers [4, 12]. For example, a mitochondrial haplotype (LOd), which was mainly observed in populations with San ancestry, was also found in the East African click-speaking Sandawe population who were, until recently, practicing hunting and gathering [53, 54]. In addition, Y chromosome haplotype B2b2 and B2b1-B2b4a lineages were only found in eastern CRHG and south Africa Khoesan-speaking populations $[55,56]$. The inferred divergence times between Niger-Congo, Nilo-Saharan, and Afroasiatic-speaking populations suggest that the ancestors of populations speaking these languages shared a common ancestor $>34$ kya. Our results suggest that the ancestor of Niger-Congo-speaking populations first split with the ancestor of Nilo-Saharan and Afroasiatic speakers and that the ancestors of Nilo-Saharan and Afroasiatic-speaking 
Table 1 Divergence time estimation between African populations speaking languages belonging to the main language phyla. All the estimates were inferred with MSMC using one individual from each population. CRHG represents central African rainforest hunter-gatherers, including east central African rainforest hunter-gatherers (East $\mathrm{CRHG}$ ) Mbuti, west central African rainforest hunter-gatherers (West CRHG) Baka, Biaka, Bakola, and Bedzan. San: Khomani San and Jul'hoan; Niger-Congo: Yoruba. Nilo-Saharan: Sengwer. Afroasiatic: Rendille. CRHG: Baka, Biaka, Bakola, Bedzan, Mbuti. The divergence times that we report here are based on relative cross-coalescent rates at 50\% (25-75\%)

\begin{tabular}{lll}
\hline Population 1 & Population 2 & Divergence time (kya) \\
\hline San & Niger-Congo & $\sim 100(59-160)$ \\
San & Nilo-Saharan & $\sim 100-120(44-160)$ \\
San & Afroasiatic & $\sim 100-120(52-160)$ \\
San & Hadza and Sandawe & $\sim 68-85(44-100)$ \\
San & CRHG & $\sim 78-85(52-120)$ \\
West CRHG & East CRHG & $\sim 44(31-50)$ \\
Niger-Congo & Afroasiatic & $\sim 34(22-54)$ \\
Niger-Congo & Nilo-Saharan & $\sim 28(17-41)$ \\
Nilo-Saharan & Afroasiatic & $\sim 16(11-16)$ \\
Hadza & Sandawe & $\sim 23(17-23)$ \\
Khomani San & Jul'hoan & $\sim 30(24-30)$ \\
\hline
\end{tabular}

populations diverged more recently at $\sim 16$ kya (16-11 kya) (Table 1). Although the divergence time estimates in this study are largely consistent with previous archeological and genetic studies, future studies that include high coverage whole genome sequencing from a larger number of individuals per population will be particularly informative for applying more complex models of demographic history based on the allele frequency spectrum [57].

\section{Identifying signatures of local adaptation}

To identify possible genomic regions contributing to local adaptation among populations, 52 individuals were merged into six "meta-ancestry" groups on the basis of shared ancestry according to ADMIXTURE analyses (Fig. 4). This included a CRHG group, consisting of Biaka, Baka, Bakola, Bedzan, and Mbuti individuals; a San group consisting of Ju|'hoan and Khomani San individuals; a Niger-Congo group consisting of Mandenka, Mende, Yoruba, Igbo, Kongo, and Esan individuals; a Sahel group consisting of Kaba, Laka, and Mada individuals; a Nilo-Saharan group consisting of Sengwer, Dinka, and Mursi individuals; and an Afroasiatic group consisting of Agaw, Amhara, Rendille, and Iraqw individuals. The $d$ statistic [58], a sum of normalized, pairwise $F_{\mathrm{ST}}$ between a focal group and all other populations, was computed for all SNPs with no more than 20\% missing data in any group. To identify candidate regions of local adaptation, variants in the top $0.1 \%$ of the empirical distribution were considered outliers. To prevent double counting variants in strong $\mathrm{LD}$, all variants with $r^{2}>0.5$ were grouped together, tagging each group by the variant with the highest $d$ value. Variants within $1 \mathrm{Mb}$ and $r^{2}>0.8$ with the tagging variants were used to define the final selection windows.

We first tested whether locally adaptive variants are enriched in functionally annotated genomic regions, including predicted promoter, dyadic, and enhancer regions from the Roadmap Epigenomics consortium [59], FANTOM5 enhancers [60], GENCODE genic regions [61], and regions conserved across mammals [62]. Using a permutation approach to measure overlap between all outlier variants and functional categories [63], we find that the outlier variants are significantly enriched in predicted promoters, dyadic regions, and enhancers, as well as introns and conserved regions $\left(P<1.0 \times 10^{-4}\right.$ for all tests). Conversely, we find a lack of significant enrichment in FANTOM5 enhancer regions $(P=0.23)$, exons $(P=0.97)$, and $3^{\prime}$ UTRs $(P=0.95)$, highlighting the importance of the noncoding and regulatory genome in the study of human complex and adaptive traits [64].

To detect associations between outlier windows and biological function, we use the Genomic Regions Enrichment of Annotations Tool (GREAT), which tests for gene ontology enrichment of nearby genes [65]. We find genes related to immune function are enriched near outlier windows across several populations (Additional file 3: Table S2), including antimicrobial humoral response in the CRHG (Binomial test, Benjamini-Hochberg $Q$ value $=2.2 \times 10^{-3}$ ), B cell homeostasis in the Niger-Congo and San $(Q=$ $4.5 \times 10^{-3}$ and $\left.4.3 \times 10^{-2}\right)$, regulation of phagocytosis and chemokine signaling in the Niger-Congo $(Q=$ $1.4 \times 10^{-2}$ and $1.6 \times 10^{-2}$ ), and cytokine production in the Nilo-Saharan populations $\left(Q=6.2 \times 10^{-3}\right)$. We also see enrichments related to cardiovascular and lipid traits, including response to low-density lipoprotein among the pastoralist Nilo-Saharan and agricultural Niger-Congo populations $\left(Q=1.7 \times 10^{-4}\right.$ and $2.7 \times$ $\left.10^{-5}\right)$ and regulation of cardiac muscle tissue growth in the Afroasiatic group $\left(Q=4.2 \times 10^{-7}\right)$. Among the San, we find enrichments for loci near genes that play a role in bone morphogenesis $\left(Q=3.0 \times 10^{-2}\right)$, notable due to the relatively gracile bone structure in the San, and near genes that play a role in renal and pancreatic development $(Q=$ $6.9 \times 10^{-3}$ and $4.5 \times 10^{-3}$ ), possible adaptations to low water availability and diet. Outlier windows among the CRHG are also enriched near genes related to abnormal thyrotroph morphology in mice $\left(Q=2.6 \times 10^{-5}\right)$, recapitulating a previously proposed connection between pituitary and thyroid function and the short stature of CRHG [21]. Genes near highly differentiated loci include the transcription factor POU1F1, which plays an important role in anterior pituitary development and has been 
previously identified as a target of selection in these populations [21], as well as PITX1, a binding partner of POU1F1 [66], and the thyroid hormone receptor THRB (mutations at this locus can lead to thyroid hormone resistance and goiter [67], which has a relatively low prevalence in CRHG populations [17]). In addition to genes related to pituitary function, genes belonging to a number of growth factor pathways are enriched near CRHG windows, including the fibroblast growth factors FGF7 and FGF10; the fibroblast growth factor receptor FGFR2; the bone morphogenetic proteins $B M P 2, B M P 4, B M P 5$, and $B M P 6$; the insulin-like growth factor receptor IGF2R; and the insulin-like growth factor binding protein IGFBP3. These findings highlight the diversity of genetic and phenotypic variation in Africa and suggest candidate loci underlying several adaptive human phenotypes, such as the short stature of CRHG, as well as possible adaptations to variable environmental pressures such as pathogen burden and diet.

\section{Conclusion}

Anatomically, modern humans originated in Africa within the past 300 kya and have continuously inhabited Africa. Prior studies found that Africans have the highest level of linguistic and genetic diversity compared to the populations in any other continent [4]. Leveraging the whole genome sequences of 92 individuals from 44 African populations, we inferred that the ancestors of present-day populations began to develop substructure as early as $\sim 200$ kya. Our analyses also identified signatures of multiple waves of migration in Africa, such as the expansion of Bantu-speaking agriculturists from west Africa to eastern and southern Africa, and migration of Nilo-Saharan- and Afroasiatic-speaking populations into East Africa. As these populations migrated and adopted new subsistence strategies, they also encountered novel environments and selective pressures, resulting in local adaptation. Although a low-resolution study suggested limited recent positive selection in Sub-Saharan Africans [68], we found strong signals of positive selection due to local adaptation in the six meta-populations based on regions of high population-specific genomic differentiation, which we find near genes playing important roles in immunity, cardiovascular function, and metabolism. In addition, we find an enrichment of genes related to fibroblast and bone growth factors, as well as pituitary function, among the CRHG populations, providing candidate genes that may underlie their unique shortstature phenotype. An increasing number of publications have identified archaic introgression in modern Africans $[48,69,70]$; its impact on the estimation of population divergence times and effective population sizes needs to be explored. In the future, a combination of phenotypic (such as anthropometric, life history, and metabolic data) and genomic (from both contemporary and ancient samples) data from Africans is needed to better understand the origin and evolution of modern humans, the genetic basis local adaptation, and the evolution of complex traits and related diseases.

\section{Methods}

\section{Sequencing and SNP calling}

The data used in this study are part of the Simons Genome diversity project [14]. They consist of 29 previously published African genome sequences and a novel set of 43 genome sequences from geographically and ethnically diverse Africans from 22 indigenous groups. The full details of the data generation were previously reported [14]. Briefly, all the samples were processed using the PCR-free paired-end library preparation protocol from Illumina. The average insert size is $314 \pm 20$ bases for libraries. The libraries were sequenced 100 base pairs at each end with average 43-fold coverage using the HiSeq2000 sequencing platform. After trimming the adaptors, the raw reads were aligned to the human reference genome (version hs37d5) using the BWA-MEM version 0.7.12 [71]. The BAM files were stored in the European Nucleotide Archive (accession number PRJEB9586 and ERP010710) and European Genome-phenome Archive (accession number EGAS00001001959). The SNPs were genotyped using the UnifiedGenotyper module in the genome analysis toolkit (GATK) [72], with a modified Wright-Fisher allele frequency spectrum prior to minimize the reference-bias in SNP calling (see more information in the SGDP manuscript). The SNP calling results were stored in the VCF format and hetfa format [14]. We extracted the autosomal SNPs that passed filter level 1 using cTools (https:// github.com/mengyao/cTools). To minimize the impact of missing data, we filtered the SNPs in LD using Plink version 1.9 [73] with the parameters --indep-pairwise 50 100.1 .

\section{Principal component and ADMIXTURE analyses}

We conducted principal component analysis using the smartpca script in the EIGENSOFT toolkit version 6.0.1 [31, 74]. Population structure was inferred using ADMIXTURE version 1.3.0 [75] with randomly starting seeds, 5-fold cross-validation (--cv 5 option) and 100 bootstraps (-B 100). We set the ancestral population number between 2 and 7 ( $K=2$ to 7$)$.

\section{Best fitting phylogenetic relationship of African populations}

The phylogenetic relationship of all African populations was constructed under the neighbor-joining framework and TREEMIX method [27], which leverages genomewide allele frequency data. First, we used the human 
ancestral alleles (ftp://ftp.1000genomes.ebi.ac.uk/vol1/ftp/ technical/retired_reference/ancestral_alignments/) as outgroups in our NJ phylogenic analysis. A set of 4,587,274 SNPs, which have high-quality ancestral alleles, were randomly selected for further phylogenetic analysis. When multiple samples were sequenced in a population, we generated a consensus sequence of each population using BioEdit version 7.2.5. The consensus sequences were used as input of MEGA (version 6) [76], and the robustness of the topology was evaluated using 100 bootstrap replicates. Phylogenetic relationships and admixture across the 44 African populations were analyzed using TREEMIX [27] with the Altai Neandertal genome sequence used as an outgroup. Variants with no more than 10\% missing data in the African samples were LD-pruned using Plink version 1.9 with the parameters --indep-pairwise 50100.1 . These data were merged with the Altai Neandertal genome [77], leaving a final set of 5,158,190 variants. TREEMIX version 1.13 was run for $0-10$ migrations, rooted by the Altai Neandertal individual, and using the parameters -global -bootstrap -noss -k 500.

\section{Effective population size and divergence time analyses}

We estimated the $\mathrm{Ne}$ and divergence time between populations using MSMC, which is a multiple sequentially Markovian coalescent method to infer effective population size and separation time between populations [38]. Since MSMC requires haplotypes as input, we phased the SNPs from the VCF files with SHAPEIT version 2.r837 [78] using the haplotypes of African populations in the 1000 Genomes Project phase 3 [20] as the reference panel (with parameters --no-mcmc, --input-ref, --include-grp AFR, --effective-size 17469, -window 0.5). We left the heterozygous sites that were not reported in the 1000 Genomes Project as unphased. This phasing strategy is the same as was used in the original SGDP study [14].

Following the instructions of MSMC, both the unphased and phased heterozygous sites were converted to the required input format [38]. We estimated the $\mathrm{Ne}$ for each sample using both phased and unphased sites. The divergence time estimation between populations was inferred with two phased genomes (one individual per population), and all the unphased sites were excluded using the "--skipAmbiguous" parameter [38]. MSMC reports the scaled population size by twice the mean autosomal per generation mutation rate $\mu$, and time-scaled by the mutation rate per year $v$, where $\mu=v g$ and $g$ is the generation time. In this study, we scaled the $\mathrm{Ne}$ size by $2 \mu=2.5 \times 10^{-8}$, assuming mutation rate per generation $v=4.3 \times 10^{-10}$ and generation time $g=29$ years. We define that the divergence of two populations based on when the relative cross-coalescence rate drops to 0.5 as in [38].

\section{Scans for local adaptation}

We first merged the populations into six meta-ancestry groups and then calculated a per site $F_{\mathrm{ST}}$ statistic adjusted for small sample sizes [58] between all group pairs for all SNPs with no more than $20 \%$ missing data in any group. For each remaining SNP in each group $i$, the statistic $d_{i}=\sum_{j \neq i}^{j}\left(F_{\mathrm{ST}}(i, j)-E\left[F_{\mathrm{ST}}(i, j)\right]\right)^{2} / \mathrm{sd}\left[F_{\mathrm{ST}}(i, j)\right]$ was calculated, where $E\left[F_{\mathrm{ST}}(i, j)\right]$ is the mean and $\operatorname{sd}\left[F_{\mathrm{ST}}(i, j)\right]$ is the standard deviation of the $F_{S T}$ between populations $i$ and $j$. Outlier variants were defined as $d$ values within the top $0.1 \%$ of the empirical distribution. To identify independent outliers (i.e., that are not in LD), percentiles were calculated for all variants (percent of variants with a $d$ value higher than a given variant) and the "-clump" command from plink v1.9 was used to cluster independent groups of outliers (with parameters --clump-p1 0.001 --clump-p2 0.01 --clump-kb 1000). This returned a set of independent "tag" variants for each independent cluster. All variants in strong LD $\left(r^{2}>0.8\right)$ with these tags were considered as potential locally adaptive. Low sample size per population limits use of methods to detect signatures of natural selection based on the allele frequency spectrum or extended haplotype homozygosity $[79,80]$.

To test for functional enrichment of outlier variants, functional genomic regions including DNase I hypersensitive sites (DHS) annotated as promoters, enhancers, and dyadic regions [59]; enhancers identified using Cap Analysis of Gene Expression (CAGE) [60]; genic regions including exons, introns, 3' UTRs, and 5' UTRs [61]; and conserved regions [61] were overlapped with outlier variants using GoShifter [63]. Ten thousand permutations were performed for each genomic category, and $P$ values were calculated as the number of permuted scores higher than the observed score, with the $P$ values less than the 0.05 family-wise error rate $\left(P<5.56 \times 10^{-3}\right)$ considered significant (Bonferroni-corrected for the number of annotations tested). To identify biological functions of genes near outlier windows, regions spanning all variants in strong $L D$ with tag variants were identified and merged. These merged windows were used as test regions in GREAT with default parameters [65]. All terms belonging to "GO Molecular Function", "GO Biological Process," "GO Cellular Component," "Mouse Phenotype," "Human Phenotype," and "Disease Ontology" with binomial and hypergeometric FDR less than 0.05 and fold enrichment greater than 2 are presented.

\section{Additional files}

Additional file 1: Table S1. Sample information in this study. (XLSX $12 \mathrm{~kb}$ ) Additional file 2: Figure S1. A phylogeny of African lineages used the Altai Neandertal as outgroup constructed using Treemix allowing for six 
migration events. Figure S2. Principal component analysis of 44 African and 32 west Eurasian populations using principal component analysis. Figure S3. ADMIXTURE analysis of 92 African and 62 West Eurasian individuals from $K=2$ to 10 . Figure S4. Effective population size of African Khoesan-speaking populations. (PDF 414 kb)

Additional file 3: Table S2. Enrichment test results of positively selected loci in different populations using GREAT. (XLSX 58 kb)

\section{Acknowledgements}

We thank the participants who donated samples and Dr. lain Mathieson at the University of Pennsylvania for insightful discussions.

\section{Funding}

Simons Foundation (SFARI 280376) and the US National Science Foundation (BCS-1032255) grants to DR funded the sequencing costs in this study, and DR is an Investigator of the Howard Hughes Medical Institute. This work was supported by National Science Foundation grants BCS-0196183 and BCS0827436 and National Institutes of Health $(\mathrm{NIH})$ grants 1R01DK104339 and 1R01GM113657 to SAT. DEK is funded through the Parasitology training grant 5-T32-Al-007532-17. MHB received a "Science Without Borders" postdoctoral fellowship from CNPq/Brazil.

\section{Availability of data and materials}

The BAM files that were used in this study are stored in the European Nucleotide Archive (Accession number: PRJEB9586 [81]) and European Genome-phenome Archive (Accession number: EGAS00001001959) [82].

\section{Authors' contributions}

DR and SAT conceived the study. SAT, TN, SO, DWM, GB, and AF assembled the samples. SF and DEK conducted the analysis. SF, DEK, and SAT wrote the manuscript with the help from other co-authors. All authors read and approved the final manuscript.

\section{Ethics approval and consent to participate}

Written informed consent was obtained from all participants, and research/ ethics approval and permits were obtained from all relevant institutions in the Simons Genome Diversity Project. The IRB approval number for Harvard Medical School (\#11681), most recently re-reviewed on July 122,017 (MOD11681-01). The experimental methods in this study comply with the principles of the Helsinki Declaration.

\section{Competing interests}

The authors declare that they have no competing interests.

\section{Publisher's Note}

Springer Nature remains neutral with regard to jurisdictional claims in published maps and institutional affiliations.

\section{Author details}

'Department of Genetics, University of Pennsylvania, Philadelphia, PA 19104, USA. ${ }^{2}$ Present Address: State Key Laboratory of Genetic Engineering, Human Phenome Institute, School of Life Sciences, Fudan University, 2005 Songhu Road, Shanghai, China. ${ }^{3}$ Department of Genetics, Harvard Medical School, Boston, MA 02115, USA. ${ }^{4}$ Broad Institute of Harvard and MIT, Cambridge, MA 02142, USA. ${ }^{5}$ Howard Hughes Medical Institute, Harvard Medical School, Boston, MA 02115, USA. ${ }^{6}$ Present Address: Division of Genetic Medicine, Vanderbilt University Medical Center, Vanderbilt University, Nashville, TN 37232, USA. 'Department of Biochemistry, Muhimbili University of Health and Allied Sciences, Dares Salaam, Tanzania. ${ }^{8}$ Center for Biotechnology Research and Development, Kenya Medical Research Institute, Nairobi, Kenya. ${ }^{9}$ Department of Biology, Addis Ababa University, Addis Ababa, Ethiopia. ${ }^{10}$ UMR 208, IRD-MNHN, Musée de I'Homme, Paris, France. ${ }^{11}$ Department of Biology, University of Pennsylvania, Philadelphia, PA 19104, USA.
Received: 7 August 2018 Accepted: 22 March 2019

Published online: 26 April 2019

\section{References}

1. Hublin J-J, Ben-Ncer A, Bailey SE, Freidline SE, Neubauer S, Skinner MM, Bergmann I, Le Cabec A, Benazzi S, Harvati K, Gunz P. New fossils from Jebel Irhoud, Morocco and the pan-African origin of Homo sapiens. Nature. 2017;546:289-92.

2. Campbell MC, Hirbo JB, Townsend JP, Tishkoff SA. The peopling of the African continent and the diaspora into the new world. Curr Opin Genet Dev. 2014;29:120-32

3. Atkinson QD. Phonemic diversity supports a serial founder effect model of language expansion from Africa. Science. 2011:332:346-9.

4. Tishkoff SA, Reed FA, Friedlaender FR, Ehret C, Ranciaro A, Froment A, Hirbo JB, Awomoyi AA, Bodo J-M, Doumbo O, et al. The genetic structure and history of Africans and African Americans. Science. 2009;324:1035-44.

5. Heine B, Nurse D. African languages: an introduction: Cambridge University Press; 2000.

6. Li S, Schlebusch C, Jakobsson M. Genetic variation reveals large-scale population expansion and migration during the expansion of Bantuspeaking peoples. Proc Biol Sci. 2014;281.

7. Boyeldieu P, Dimmendaal GJ, Fleisch A, Frajzyngier Z, Güldemann T, Nougayrol P, Porkhomovsky V, Vossen R: Problems of linguistic-historical reconstruction in Africa (SUGIA Sprache und Geschichte in Afrika). 1st edition edn: Rüdiger Köppe; 2008.

8. Sands BE: Eastern and southern African Khoisan: evaluating claims of distant linguistic relationships. R. Köppe; 1998.

9. Campbell MC, Tishkoff SA. The evolution of human genetic and phenotypic variation in Africa. Curr Biol. 2010;20:R166-73.

10. Campbell MC, Tishkoff SA. African genetic diversity: implications for human demographic history, modern human origins, and complex disease mapping. Annu Rev Genomics Hum Genet. 2008;9:403-33.

11. Beltrame $M H$, Rubel MA, Tishkoff SA. Inferences of African evolutionary history from genomic data. Curr Opin Genet Dev. 2016;41:159-66.

12. Tishkoff SA, Gonder MK, Henn BM, Mortensen H, Knight A, Gignoux C, Fernandopulle N, Lema G, Nyambo TB, Ramakrishnan U, et al. History of click-speaking populations of Africa inferred from mtDNA and $Y$ chromosome genetic variation. Mol Biol Evol. 2007;24:2180-95.

13. Henn BM, Gignoux CR, Jobin M, Granka JM, Macpherson JM, Kidd JM, Rodríguez-Botigué L, Ramachandran S, Hon L, Brisbin A, et al. Huntergatherer genomic diversity suggests a southern African origin for modern humans. Proc Natl Acad Sci U S A. 2011:108:5154-62.

14. Mallick S, Li H, Lipson M, Mathieson I, Gymrek M, Racimo F, Zhao M, Chennagiri N, Nordenfelt S, Tandon A, et al. The Simons Genome Diversity Project: 300 genomes from 142 diverse populations. Nature. 2016;538:201-6.

15. Ranciaro A, Campbell MC, Hirbo JB, Ko W-Y, Froment A, Anagnostou P, Kotze MJ, Ibrahim M, Nyambo T, Omar SA, Tishkoff SA. Genetic origins of lactase persistence and the spread of pastoralism in Africa. Am J Hum Genet. 2014:94:496-510.

16. Tishkoff SA, Reed FA, Ranciaro A, Voight BF, Babbitt CC, Silverman JS, Powell K, Mortensen HM, Hirbo JB, Osman M, et al. Convergent adaptation of human lactase persistence in Africa and Europe. Nat Genet. 2007:39:31-40.

17. Jarvis JP, Scheinfeldt LB, Soi S, Lambert C, Omberg L, Ferwerda B, Froment A, Bodo J-M, Beggs W, Hoffman G, et al. Patterns of ancestry, signatures of natural selection, and genetic association with stature in Western African pygmies. PLoS Genet. 2012;8:e1002641.

18. Perry GH, Foll M, Grenier J-C, Patin E, Nédélec Y, Pacis A, Barakatt M, Gravel S, Zhou X, Nsobya SL, et al. Adaptive, convergent origins of the pygmy phenotype in African rainforest hunter-gatherers. Proc Natl Acad Sci U S A. 2014;111:E3596-603.

19. Fan S, Hansen MEB, Lo Y, Tishkoff SA. Going global by adapting local: a review of recent human adaptation. Science. 2016;354:54-9.

20. Genomes Project C, Auton A, Brooks LD, Durbin RM, Garrison EP, Kang HM, Korbel JO, Marchini JL, McCarthy S, GA MV, Abecasis GR. A global reference for human genetic variation. Nature. 2015;526:68-74

21. Lachance J, Vernot B, Elbers CC, Ferwerda B, Froment A, Bodo J-M, Lema G, Fu W, Nyambo TB, Rebbeck TR, et al. Evolutionary history and adaptation from high-coverage whole-genome sequences of diverse African huntergatherers. Cell. 2012;150:457-69.

22. Gurdasani D, Carstensen T, Tekola-Ayele F, Pagani L, Tachmazidou I, Hatzikotoulas K, Karthikeyan S, lles L, Pollard MO, Choudhury A, et al. The 
African Genome Variation Project shapes medical genetics in Africa. Nature. 2015;517:327-32.

23. Dobon B, Hassan HY, Laayouni H, Luisi P, Ricano-Ponce I, Zhernakova A, Wijmenga C, Tahir H, Comas D, Netea MG, Bertranpetit J: The genetics of East African populations: a Nilo-Saharan component in the African genetic landscape. Sci Rep. 2015;5:9996.

24. Hassan HY, Underhill PA, Cavalli-Sforza LL, Ibrahim ME. Y-chromosome variation among Sudanese: restricted gene flow, concordance with language, geography, and history. Am J Phys Anthropol. 2008;137:316-23.

25. Cerný V, Salas A, Hájek M, Zaloudková M, Brdicka R. A bidirectional corridor in the Sahel-Sudan belt and the distinctive features of the Chad Basin populations: a history revealed by the mitochondrial DNA genome. Ann Hum Genet. 2007;71:433-52.

26. Černý V, Pereira L, Musilová E, Kujanová M, Vašíková A, Blasi P, Garofalo L, Soares P, Diallo I, Brdička R, Novelletto A. Genetic structure of pastoral and farmer populations in the African Sahel. Mol Biol Evol. 2011;28:2491-500.

27. Pickrell JK, Pritchard JK. Inference of population splits and mixtures from genome-wide allele frequency data. PLoS Genet. 2012;8:e1002967.

28. Scheinfeldt L, Soi S, Lambert C, Ko W-Y, Ranciaro A, Thompson S, Jibril H, William B, Muntaser I, Thomas N, et al: Genomic evidence for shared common ancestry of East African hunting-gathering populations and insights into local adaptation. Proc Natl Acad Sci U S A.

29. Semino O, Santachiara-Benerecetti AS, Falaschi F, Cavalli-Sforza LL, Underhill PA. Ethiopians and Khoisan share the deepest clades of the human Ychromosome phylogeny. Am J Hum Genet. 2002;70:265-8.

30. Ambrose SH. Archaeological and linguistic reconstructions of history in East Africa. In: Ehret C, Posnansky M, editors. The archaeological and linguistic reconstruction of African history. Berkeley: University of California Press; 1982. p. 104-57.

31. Patterson N, Price AL, Reich D. Population structure and eigenanalysis. PLoS Genet. 2006;2:e190.

32. Arauna LR, Mendoza-Revilla J, Mas-Sandoval A, Izaabel H, Bekada A Benhamamouch S, Fadhlaoui-Zid K, Zalloua P, Hellenthal G, Comas D. Recent historical migrations have shaped the gene pool of Arabs and Berbers in North Africa. Mol Biol Evol. 2017;34:318-29.

33. Behar DM, Villems R, Soodyall H, Blue-Smith J, Pereira L, Metspalu E, Scozzari $\mathrm{R}$, Makkan H, Tzur S, Comas D, et al. The dawn of human matrilineal diversity. Am J Hum Genet. 2008:82:1130-40.

34. Vansina J. New linguistic evidence and 'the Bantu expansion'. J Afr Hist. 1995;36:173.

35. Ehret C, Posnansky M. The archaeological and linguistic reconstruction of African history: University of California Press; 1982.

36. Holden CJ. Bantu language trees reflect the spread of farming across sub-Saharan Africa: a maximum-parsimony analysis. Proc Biol Sci. 2002;269:793-9.

37. Culture history in the Southern Sudan: archaeology, linguistics, and ethnohistory (Memoir No. 8 of the British Institute in Eastern Africa). British Institute in Eastern Africa; 1983.

38. Schiffels $S$, Durbin R. Inferring human population size and separation history from multiple genome sequences. Nat Genet. 2014;46:919-25.

39. Gronau I, Hubisz MJ, Gulko B, Danko CG, Siepel A. Bayesian inference of ancient human demography from individual genome sequences. Nat Genet. 2011:43:1031-4.

40. Kim HL, Ratan A, Perry GH, Montenegro A, Miller W, Schuster SC. Khoisan hunter-gatherers have been the largest population throughout most of modern-human demographic history. Nat Commun. 2014;5:5692.

41. Batini C, Lopes J, Behar DM, Calafell F, Jorde LB, van der Veen L, QuintanaMurci L, Spedini G, Destro-Bisol G, Comas D. Insights into the demographic history of African Pygmies from complete mitochondrial genomes. Mol Biol Evol. 2011;28:1099-110

42. Veeramah KR, Wegmann D, Woerner A, Mendez FL, Watkins JC, DestroBisol G, Soodyall H, Louie L, Hammer MF. An early divergence of KhoeSan ancestors from those of other modern humans is supported by an ABC-based analysis of autosomal resequencing data. Mol Biol Evol. 2012;29:617-30.

43. Henn BM, Botigué LR, Gravel S, Wang W, Brisbin A, Byrnes JK, Fadhlaoui-Zid K, Zalloua PA, Moreno-Estrada A, Bertranpetit J, et al. Genomic ancestry of North Africans supports back-to-Africa migrations. PLoS Genet. 2012;8:e1002397.

44. Hellenthal G, Auton A, Falush D. Inferring human colonization history using a copying model. PLoS Genet. 2008;4:e1000078.
45. Li H, Durbin R. Inference of human population history from individual whole-genome sequences. Nature. 2011;475:493-6.

46. Knight A, Underhill PA, Mortensen HM, Zhivotovsky LA, Lin AA, Henn BM, Louis D, Ruhlen M, Mountain JL. African Y chromosome and mtDNA divergence provides insight into the history of click languages. Curr Biol. 2003;13:464-73.

47. Zhivotovsky LA, Rosenberg NA, Feldman MW. Features of evolution and expansion of modern humans, inferred from genomewide microsatellite markers. Am J Hum Genet. 2003;72:1171-86.

48. Schlebusch CM, Malmström H, Günther T, Sjödin P, Coutinho A, Edlund H, Munters AR, Vicente M, Steyn M, Soodyall H, et al: Southern African ancient genomes estimate modern human divergence to 350,000 to 260,000 years ago. Science 2017:eaao6266.

49. Pickrell JK, Patterson N, Barbieri C, Berthold F, Gerlach L, Güldemann T, Kure B, Mpoloka SW, Nakagawa H, Naumann C, et al. The genetic prehistory of southern Africa. Nat Commun. 2012;3:1143.

50. Schlebusch CM, Skoglund P, Sjödin P, Gattepaille LM, Hernandez D, Jay F, Li $S$, De Jongh $M$, Singleton $A$, Blum MGB, et al. Genomic variation in seven Khoe-San groups reveals adaptation and complex African history. Science. 2012;338:374-9.

51. Quintana-Murci L, Quach H, Harmant C, Luca F, Massonnet B, Patin E, Sica L, Mouguiama-Daouda P, Comas D, Tzur S, et al. Maternal traces of deep common ancestry and asymmetric gene flow between Pygmy hunter-gatherers and Bantu-speaking farmers. Proc Natl Acad Sci U S A. 2008;105:1596-601

52. Batini C, Coia V, Battaggia C, Rocha J, Pilkington MM, Spedini G, Comas D, Destro-Bisol G, Calafell F. Phylogeography of the human mitochondrial L1C haplogroup: genetic signatures of the prehistory of Central Africa. Mol Phylogenet Evol. 2007;43:635-44.

53. Gonder MK, Mortensen HM, Reed FA, de Sousa A, Tishkoff SA. WholemtDNA genome sequence analysis of ancient African lineages. Mol Biol Evol. 2007;24:757-68.

54. Barbieri C, Vicente M, Rocha J, Mpoloka SW, Stoneking M, Pakendorf B. Ancient substructure in early mtDNA lineages of southern Africa. Am J Hum Genet. 2013;92:285-92.

55. Batini C, Ferri G, Destro-Bisol G, Brisighelli F, Luiselli D, Sánchez-Diz P, Rocha J, Simonson T, Brehm A, Montano V, et al. Signatures of the preagricultural peopling processes in sub-Saharan Africa as revealed by the phylogeography of early Y chromosome lineages. Mol Biol Evol. 2011;28:2603-13.

56. Barbieri C, Hübner A, Macholdt E, Ni S, Lippold S, Schröder R, Mpoloka SW Purps J, Roewer L, Stoneking M, Pakendorf B. Refining the Y chromosome phylogeny with southern African sequences. Hum Genet. 2016;135:541-53.

57. Kamm JA, Terhorst J, Durbin R, Song YS: Efficiently inferring the demographic history of many populations with allele count data. BioRxiv 2018.

58. Akey JM, Ruhe AL, Akey DT, Wong AK, Connelly CF, Madeoy J, Nicholas TJ, Neff MW. Tracking footprints of artificial selection in the dog genome. Proc Natl Acad Sci U S A. 2010;107:1160-5.

59. Roadmap Epigenomics C, Kundaje A, Meuleman W, Ernst J, Bilenky M, Yen A, Heravi-Moussavi A, Kheradpour P, Zhang Z, Wang J, et al. Integrative analysis of 111 reference human epigenomes. Nature. 2015;518:317-30.

60. Lizio M, Harshbarger J, Shimoji H, Severin J, Kasukawa T, Sahin S, Abugessaisa I, Fukuda S, Hori F, Ishikawa-Kato S, et al. Gateways to the FANTOM5 promoter level mammalian expression atlas. Genome Biol. 2015;16:22

61. Harrow J, Frankish A, Gonzalez JM, Tapanari E, Diekhans M, Kokocinski F, Aken BL, Barrell D, Zadissa A, Searle S, et al. GENCODE: the reference human genome annotation for The ENCODE Project. Genome Res. 2012:22:1760-74.

62. Lindblad-Toh K, Garber M, Zuk O, Lin MF, Parker BJ, Washietl S, Kheradpour P, Ernst J, Jordan G, Mauceli E, et al. A high-resolution map of human evolutionary constraint using 29 mammals. Nature. 2011;478:476-82.

63. Trynka G, Westra H-J, Slowikowski K, Hu X, Xu H, Stranger BE, Klein RJ, Han $B$, Raychaudhuri S. Disentangling the effects of colocalizing genomic annotations to functionally prioritize non-coding variants within complextrait loci. Am J Hum Genet. 2015;97:139-52.

64. Fraser HB. Gene expression drives local adaptation in humans. Genome Res. 2013;23:1089-96.

65. McLean CY, Bristor D, Hiller M, Clarke SL, Schaar BT, Lowe CB, Wenger AM, Bejerano G. GREAT improves functional interpretation of cis-regulatory regions. Nat Biotechnol. 2010;28:495-501. 
66. Szeto DP, Ryan AK, O'Connell SM, Rosenfeld MG. P-OTX: a PIT-1-interacting homeodomain factor expressed during anterior pituitary gland development. Proc Natl Acad Sci U S A. 1996;93:7706-10.

67. Rivas AM, Lado-Abeal J. Thyroid hormone resistance and its management. Proc. 2016;29:209-11.

68. Granka JM, Henn BM, Gignoux CR, Kidd JM, Bustamante CD, Feldman MW. Limited evidence for classic selective sweeps in African populations. Genetics. 2012;192:1049-64.

69. Skoglund P, Thompson JC, Prendergast ME, Mittnik A, Sirak K, Hajdinjak M, Salie T, Rohland N, Mallick S, Peltzer A, et al. Reconstructing prehistoric African population structure. Cell. 2017;171:59-71 e21.

70. Gallego Llorente M, Jones ER, Eriksson A, Siska V, Arthur KW, Arthur JW, Curtis MC, Stock JT, Coltorti M, Pieruccini P, et al. Ancient Ethiopian genome reveals extensive Eurasian admixture in Eastern Africa. Science. 2015:350:820-2.

71. Eleftherohorinou H, Wright V, Hoggart C, Hartikainen AL, Jarvelin MR, Balding D, Coin L, Levin M. Pathway analysis of GWAS provides new insights into genetic susceptibility to 3 inflammatory diseases. PLoS One. 2009;: :e8068.

72. DePristo MA, Banks E, Poplin R, Garimella KV, Maguire JR, Hartl C, Philippakis AA, del Angel G, Rivas MA, Hanna M, et al. A framework for variation discovery and genotyping using next-generation DNA sequencing data. Nat Genet. 2011:43:491-8.

73. Purcell S, Neale B, Todd-Brown K, Thomas L, Ferreira MAR, Bender D, Maller J, Sklar P, de Bakker PIW, Daly MJ, Sham PC. PLINK: a tool set for wholegenome association and population-based linkage analyses. Am J Hum Genet. 2007;81:559-75

74. Price AL, Patterson NJ, Plenge RM, Weinblatt ME, Shadick NA, Reich D. Principal components analysis corrects for stratification in genome-wide association studies. Nat Genet. 2006;38:904-9.

75. Alexander DH, Novembre J, Lange K. Fast model-based estimation of ancestry in unrelated individuals. Genome Res. 2009;19:1655-64.

76. Tamura K, Stecher G, Peterson D, Filipski A, Kumar S. MEGA6: molecular evolutionary genetics analysis version 6.0. Mol Biol Evol. 2013;30:2725-9.

77. Prufer K, Racimo F, Patterson N, Jay F, Sankararaman S, Sawyer S, Heinze A Renaud G, Sudmant PH, de Filippo C, et al. The complete genome sequence of a Neanderthal from the Altai Mountains. Nature. 2014:505:43-9.

78. Delaneau O, Marchini J, Zagury J-F. A linear complexity phasing method for thousands of genomes. Nat Methods. 2011;9:179-81.

79. Chen H, Patterson N, Reich D. Population differentiation as a test for selective sweeps. Genome Res. 2010;20:393-402.

80. Voight BF, Kudaravalli S, Wen X, Pritchard JK. A map of recent positive selection in the human genome. PLoS Biol. 2006;4:e72.

81. Mallick S, Li H, Lipson M, Mathieson I, Gymrek M, Racimo F, Zhao M, Chennagiri N, Nordenfelt S, Tandon A, et al: The Simons Genome Diversity Project: 300 genomes from 142 diverse populations. Datasets European Nucleotide Archive Available at https://www.ebi.ac.uk/ena/data/view/ PRJEB9586

82. Fan S, Kelly DE, Beltrame MH, Hansen MEB, Mallick S, Ranciaro A, Hirbo JB, Thompson S, Beggs W, Nyambo T, et al: African evolutionary history inferred from whole genome sequence data of 44 indigenous African populations. Datasets European Genome-phenome Archive Available at: https://www.ebi. ac.uk/ega/studies/EGAS00001001959

Ready to submit your research? Choose BMC and benefit from:

- fast, convenient online submission

- thorough peer review by experienced researchers in your field

- rapid publication on acceptance

- support for research data, including large and complex data types

- gold Open Access which fosters wider collaboration and increased citations

- maximum visibility for your research: over $100 \mathrm{M}$ website views per year

At BMC, research is always in progress.

Learn more biomedcentral.com/submissions 